\title{
Tricuspid Valve Atresia
}

National Cancer Institute

\section{Source}

National Cancer Institute. Tricuspid Valve Atresia. NCI Thesaurus. Code C85202.

A cong enital heart defect characterized by the complete lack of formation of the tricuspid valve. Cyanosis is the predominant clinical symptom. 